\title{
OPINIÃO PÚBLICA NO TWITTER: ANÁLISE DA INDICAÇÃO DE ALEXANDRE DE MORAES AO STF
}

Felipe Bonow Soares

Doutorando no programa de Pós-graduação em Comunicação e Informação na UFRGS, pesquisador do MIDIARS - Grupo de Pesquisa em Mídia, Discurso e Análise de Redes

Sociais.

felipebsoares@hotmail.com. UFRGS, professora e pesquisadora do curso de Jornalismo da UFPel e pesquisadora do MIDIARS - Grupo de Pesquisa em Mídia, Discurso e Análise de Redes Sociais. raquel@raquelrecuero.com

\begin{abstract}
Resumo
Este estudo busca discutir e analisar a construção da opinião pública no Twitter, tomando como estudo de caso a nomeação de Alexandre de Moraes para substituir Teori Zavascki como ministro do Supremo Tribunal Federal. A base teórica é formada a partir das relações entre o conceito de esfera pública e os sites de redes sociais. Para realizar esta análise, foram adotados métodos mistos, baseados na análise de contingência e na análise de redes. O corpus deste estudo é composto por 15.125 tweets, coletados do Twitter utilizando "Alexandre de Moraes" como termo de coleta. Os dados foram analisados por meio das coocorrências entre os conceitos dos tweets, sendo possível observar os principais assuntos discutidos e posicionamentos dos usuários, em sua maioria contrários à indicação de Moraes.
\end{abstract}

Palavras-chave: Análise de contingência. Análise de redes. Esfera pública. Opinião pública.

\section{PUBLIC OPINION ON TWITTER: ALEXANDRE DE MORAES 'S INDICATION TO STF}

\begin{abstract}
This study seeks to discuss and analyze the construction of public opinion on Twitter with the case of Alexandre de Moraes's indication to substitute Teori Zavascki as a minister in Supreme Federal Court. The theoretical background is based on the relations about the public sphere concept and the social network sites. To perform this analysis mixed methods were adopted, based on contingecy analysis and network analysis. This study corpus is formed by 15.125 tweets, collected from Twitter, using "Alexandre de Moraes" as the referencial term. This data was analyzed by observing the coocurrences between the concepts of the tweets, allowing us to identify the main subjects and the users opinion, mostly against the indication of Moraes.
\end{abstract}

Keywords: Contingency analysis. Network analysis. Public sphere. Public opinion

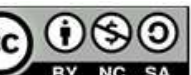

Esta obra está licenciada sob uma Licença Creative Commons Atribuição 4.0 Internacional (CC BY-NC-AS 4.0).

LOGEION: Filosofia da informação, Rio de Janeiro, v. 3 n. 2, p. 18-37, mar./ago. 2017. 


\section{Introdução}

Uma das questões mais importantes a respeito da difusão de informações em sites de rede social está no seu papel na formação da opinião pública. Isso porque as informações circulam de modo diferente nessas ferramentas. São os atores que, a partir de motivações baseadas em suas percepções individuais, filtram e replicam as informações, tornando-as visíveis para o restante da rede (RECUERO, 2010). Essas ações terminam por tornar algumas informações visíveis e outras não, construindo discursos e silenciando outros. Há, assim, um papel fundamental da rede sobre a circulação de informações. Mais do que isso, há atores que, pela sua posição, são muito mais visíveis do que outros, tornando seu papel de filtro mais relevante na rede como um todo, uma vez que suas informações têm maiores chances de ver replicadas do que as demais (CHA et al, 2010). Diante destas questões, este artigo busca investigar os processos de construção da opinião pública e da esfera pública no Twitter ${ }^{1}$ no Brasil, a partir de um estudo de caso: a nomeação de Alexandre de Moraes para ministro do STF.

No dia 6 de fevereiro de 2017, Alexandre de Moraes foi indicado para ocupar o cargo de ministro do Supremo Tribunal Federal (STF) pelo presidente do Brasil Michel Temer esta foi a primeira indicação de Temer para o cargo durante o seu governo. Quando indicado, Moraes era ministro da Justiça. Moraes foi indicado para ocupar a vaga de Teori Savascki, que morreu em acidente de avião no dia 19 de janeiro. Teori Savascki era o relator da Lava Jato no STF e estava analisando documentos que indicavam a participação de diversos políticos no esquema.

Discutiremos neste artigo se as manifestações publicadas em espaços como o Twitter também fazem parte da opinião pública (BASTOS, 2011; RECUERO, BASTOS, ZAGO, 2015). Deste modo, a observação do que é dito no Twitter e a forma como circulam informação e opinião na rede observada, podem indicar que tipo de relação há entre a conversação no Twitter e a formação da opinião pública. O Twitter foi selecionado para este estudo porque há circulação mais aberta de informações, já que todos os perfis são públicos, permitindo também uma coleta de dados mais acessível. Para a análise, foram coletados 15.125 tweets $^{2}$ em 8 de fevereiro de 2017. Estes serão analisados por meio da análise de contingência e da análise de redes. O que se pretende com a análise é: 1) identificar que tópicos são debatidos sobre a indicação de Moraes; 2) analisar que posicionamentos são

\footnotetext{
${ }^{1}$ www.twitter.com.

${ }^{2}$ Mensagem de até 140 caracteres publicada por usuários no Twitter.
} 
adotados pelos usuários do Twitter no corpus coletado; 3) observar como perfis de maior influência na rede surgem nos dados; 4) discutir a questão da esfera e opinião pública no contexto analisado.

\section{Esfera pública, mídia social e opinião pública}

Para discutir como a mídia social pode ser percebida como um espaço de construção da opinião pública, precisamos discutir o conceito de esfera pública.

A descrição da esfera pública burguesa por Habermas (1984) é um marco nos estudos da área. Esta esfera pública é chamada burguesa porque, no período analisado pelo autor, a comunicação ao público raramente atinge a todos, mas somente uma camada mais culta da sociedade, que surgida juntamente com o moderno aparelho de Estado é conhecida como burguesia (HABERMAS, 1984, p. 37). Para o autor, esta esfera pública é o espaço onde as pessoas privadas se posicionam como um fórum com a intenção de "obrigar o poder público a se legitimar perante a opinião pública” (p. 40). A esfera pública é percebida como um espaço de participação, onde o público pode discutir e debater questões relevantes para a sociedade. Em momento posterior, Habermas (1997, p. 92) atualiza o seu conceito, definindo esfera pública como "uma rede adequada para a comunicação de conteúdos, tomadas de posição e opiniões; nela os fluxos comunicacionais são filtrados e sintetizados, a ponto de se condensarem em opiniões públicas enfeixadas em temas”. Este conceito atrela a esfera pública à construção da opinião pública, e observando este espaço público onde a opinião é constituída como um conjunto de arenas (p. 107). Outro ponto importante apontado pelo autor em sua revisão é a presença de influenciadores, indivíduos com prestígio social que podem influenciar a formação de opinião nas arenas onde possuem reconhecimento (p. 95-96).

A aplicação do conceito de esfera pública aos sites de rede social na Internet já foi debatida por vários autores. Os sites de rede social são ferramentas que permite a reinscrição da estrutura das redes sociais no ciberespaço. O conceito de site de rede social como ferramenta que permite a publicação das redes sociais, a navegação pelas conexões e a interação foi cunhado por Boyd \& Ellison (2007). Esses sites, entretanto, além de permitir a reinscrição das redes sociais, as modificam. Eles permitem que essas conexões entre os atores funcionem como vias por onde a informação está permanentemente circulando. A partir da estrutura da rede, os atores decidem dar ou não visibilidade para as informações. Essas ações, de modo coletivo, acabam influenciando as informações que circulam e criando processos de 
difusão, denominados aqui como mídia social a partir de Recuero, Bastos \& Zago (2015). Esses processos são importantes para a compreensão da influência da esfera pública digital na construção da opinião pública.

Bastos (2011) se apropria dos estudos de Luhmann - que possuem características semelhantes ao segundo conceito de Habermas (1997) - para defender que a opinião pública circula em uma rede de comunicação que constantemente se relaciona entre múltiplos temas. Ele discute a esfera pública a partir da metáfora de anéis de cebolas: ciclos de comunicação que se relacionam entre os clusters (grupos) que interagem entre si - como as arenas de Habermas (1997, p. 107). Neste caso, a informação vai sendo propagada entre as várias esferas. Bruns \& Highfield (2016), por outro lado, discutem a presença de micro esferas públicas, que chamam de "esferículas públicas", constituídas nos vários clusters dentro dos sites de rede social. Também Recuero, Bastos e Zago (2015, p. 35) defendem que os SRS “podem ser compreendidos como elementos ampliadores da esfera pública que proporcionam um espaço onde, além da socialização, os atores podem expressar e reproduzir opiniões políticas e ideias que contribuem para o debate público". Essa ação dos atores, reproduzindo, ampliando a visibilidade e comentando informações é que vai dar a dimensão de propagação da informação que gera os debates. A própria construção da opinião pública, assim, depende das ações de difusão de informações que são tomadas pelos atores na rede.

Quando há mobilizações que proporcionam circulação de opiniões de usuários na rede, há um processo de influência na formação da opinião pública. Observando o âmbito político, é possível afirmar que as discussões na internet são compostas frequentemente pela participação e mobilização de cidadãos em geral, não apenas de partidos políticos e suas militâncias (GIBSON, 2013, p. 29). No contexto brasileiro é possível citar os protestos de junho de $2013^{3}$ e as organizações populares que surgiram posteriormente, como o Movimento Vem pra Rua ${ }^{4}$ e o Movimento Brasil Livre ${ }^{5}$, ambos com posicionamento de oposição ao governo de Dilma Rousseff e responsáveis por novas manifestações, especialmente em 2015 e 2016. Este tipo de mobilização popular, ao influenciar a formação da opinião pública, acaba por legitimar - ou deslegitimar, como no caso dos movimentos de oposição à Dilma, que apoiaram seu impeachment (GARCIA et al, 2016) - as ações do poder público.

\footnotetext{
${ }^{3}$ Protestos que iniciaram em função dos aumentos de passagens de ônibus e alcançaram manifestações que envolveram milhões de pessoas ao redor do Brasil, gerando reivindicações mais heterogêneas.

${ }^{4}$ http://www.vemprarua.net/.

${ }^{5}$ https://mbl.org.br/.
} 
A opinião pública é fruto de posicionamentos de indivíduos sobre temas específicos. Sendo assim, possui como tendência a heterogeneidade de opiniões em sua formação, visto que é fruto de perspectivas de indivíduos sobre os temas debatidos. Azevedo (2004, p. 60) sugere, inclusive, que se poderia falar em "opiniões públicas". O tipo de circulação de mensagens e o poder persuasivo de atores influentes, por exemplo, podem fortalecer um tipo de posicionamento sobre o tema debatido, o que não impede a existência de outras opiniões adotadas por outros grupos ou atores. Assim, ao analisar um recorte de manifestações sobre a indicação de Moraes ao STF, é possível identificar tendências da opinião pública, mas que não pode excluir a possibilidade de outros posicionamentos sobre o assunto. Além disso, com a análise proposta, é possível discutir como circula a informação/opinião dos atores no corpus coletado, observando se há interação entre os clusters (como sugere BASTOS, 2011) ou se existe a formação de "esferículas públicas" (BRUNS; HIGHFIELD, 2016) de forma mais isolada. O papel dos influenciadores (HABERMAS, 1997) também pode ser observado na forma como as mensagens são difundidas, identificando se existem atores responsáveis por induzir a opinião de outros atores de sua rede, assim como possibilitar a interação com outros clusters por sua capacidade de visualização na rede (CHA et al, 2010).

\section{Métodos}

Nosso objetivo geral, neste trabalho, é investigar os processos de construção da opinião pública e da esfera pública no Twitter. Para tanto, focaremos em um estudo de caso a respeito da indicação do ministro do STF Alexandre Moraes, a partir de quatro pontos: 1) identificar que tópicos são debatidos sobre a indicação de Moraes; 2) analisar que posicionamentos são adotados pelos usuários do Twitter no corpus coletado; 3) observar como perfis de maior influência na rede surgem nos dados; 4) discutir a questão da esfera e opinião pública no contexto analisado.

A abordagem utilizada neste estudo é baseada em análise de contingência e a análise de redes. Esta estratégia metodológica foi adotada como meio de identificar os discursos adotados pelos usuários do Twitter sobre a indicação de Alexandre de Moraes ao STF. Por meio da metodologia proposta, é possível perceber os nuances das linhas discursivas, assim como observar que tipos de posicionamentos são majoritários nas manifestações no Twitter, assim como discutir o papel dos influenciadores e da circulação de informação e opinião para a formação da opinião pública. 
A análise de contingência é uma das técnicas da análise de conteúdo. Ela foca na observação de associações entre conceitos, analisando suas co-ocorrências (RECUERO, 2015, p. 555). Ou seja, a análise de contingência busca identificar os sentidos presentes em um conjunto de dados por meio da frequência de repetição e das relações entre os termos que o compõem. No caso deste estudo, busca-se observar quais são as palavras mais frequentes nos tweets coletados e como elas se relacionam, aparecendo de maneira conjunta nas sentenças produzidas pelos usuários.

A análise de redes oferece as métricas para a análise, são utilizadas para descrever as relações entre os nós e suas conexões (RECUERO; BASTOS; ZAGO, 2015, p. 39). Neste estudo, foram utilizadas duas métricas: (1) o grau, número de conexões de cada termo, representado visualmente pelo tamanho do nó; e (2) a modularidade, que gera grupos (clusters) a partir das conexões entre os conceitos, que pode ser observado no grafo pelas cores dos nós. Para a visualização dos dados, também utilizamos grafos (representações de uma rede em forma de imagem), que são compostos por nós (os conceitos selecionados para análise) e suas conexões, demonstrando visualmente o conjunto de inter-relações entre os elementos que o compõem (RECUERO; BASTOS; ZAGO, 2015, p. 45). A construção dos grafos é feita por meio de algoritmos, que posicionam os nós conforme o critério adotado para a observação dos dados, no caso deste estudo, o algoritmo utilizado foi o Force Atlas, que aproxima os grupos e centraliza os nós de maior grau.

Para a análise aqui proposta, foi realizada uma busca no Twitter a partir do termo "Alexandre de Moraes" no dia 8 de fevereiro de 2017, às 8 h através do software NodeXL . Foram coletados 15.125 tweets. Estes dados foram processados para a identificar a frequência e as coocorrências entre os termos selecionados. Para esta análise foram selecionados 74 termos (com no mínimo 100 menções, como critério para selecionar os termos que foram mais repetidos nos tweets, observando, assim, os posicionamentos mais frequentes), agrupados em 66 conceitos (termos como "desfiliação" e "desfiliar", por exemplo, foram associados ao conceito "desfiliação" em função de sua proximidade de sentido, da mesma forma os termos "indica", "indicação" e "indicado" foram posicionados no conceito “indicação"), gerando 2022 coocorrências. Por fim, foi formado um grafo com base no algoritmo e nas métricas acima citadas.

De forma complementar, também analisamos a rede em torno da conversação, utilizando métricas de: (1) grupabilidade por cluster (algoritmo do NodeXL); (2) grau de

${ }^{6}$ https://nodexl.codeplex.com/ 
intermediação (betweenness centrality), que indica o quão "ponte" entre vários grupos é um determinado nó (o que pode indicar um nó muito citado por diferentes clusters); e (3) grau de entrada, de modo a perceber os principais grupos. Cada conexão nesta rede representa uma menção ou retweet (RT) e os grupos estão separados em torno da tendência de participar de uma ou outra conversação. Também foi gerado um grafo para a observação dessa circulação de informações. Observamos também, de modo qualitativo, as mensagens dos principais nós que aparecem na rede e os tweets com maior impacto desses atores.

\section{Análise dos dados}

Para as análises da formação da opinião pública no recorte selecionado e da forma como circula a informação/opinião na rede, esta análise será dividida em duas etapas. $\mathrm{Na}$ primeira, observamos a análise da rede coletada, identificando usuários importantes e como se forma a esfera de discussão no recorte de dados do Twitter. Na segunda, utilizamos a análise de contingência e de conteúdo para verificar que tipo de posicionamentos são mais frequentes entre os usuários da rede e qual é a opinião pública que pode ser observada no recorte analisado.

\subsection{Análise da rede de conversação}

$\mathrm{Na}$ figura a seguir (Figura 1), vemos os principais grupos de atores que estão participando das conversações em torno da indicação de Moraes no Twitter, nos dados coletados. Os vários grupos representam redes de conversação, conforme explicamos na sessão 3. 


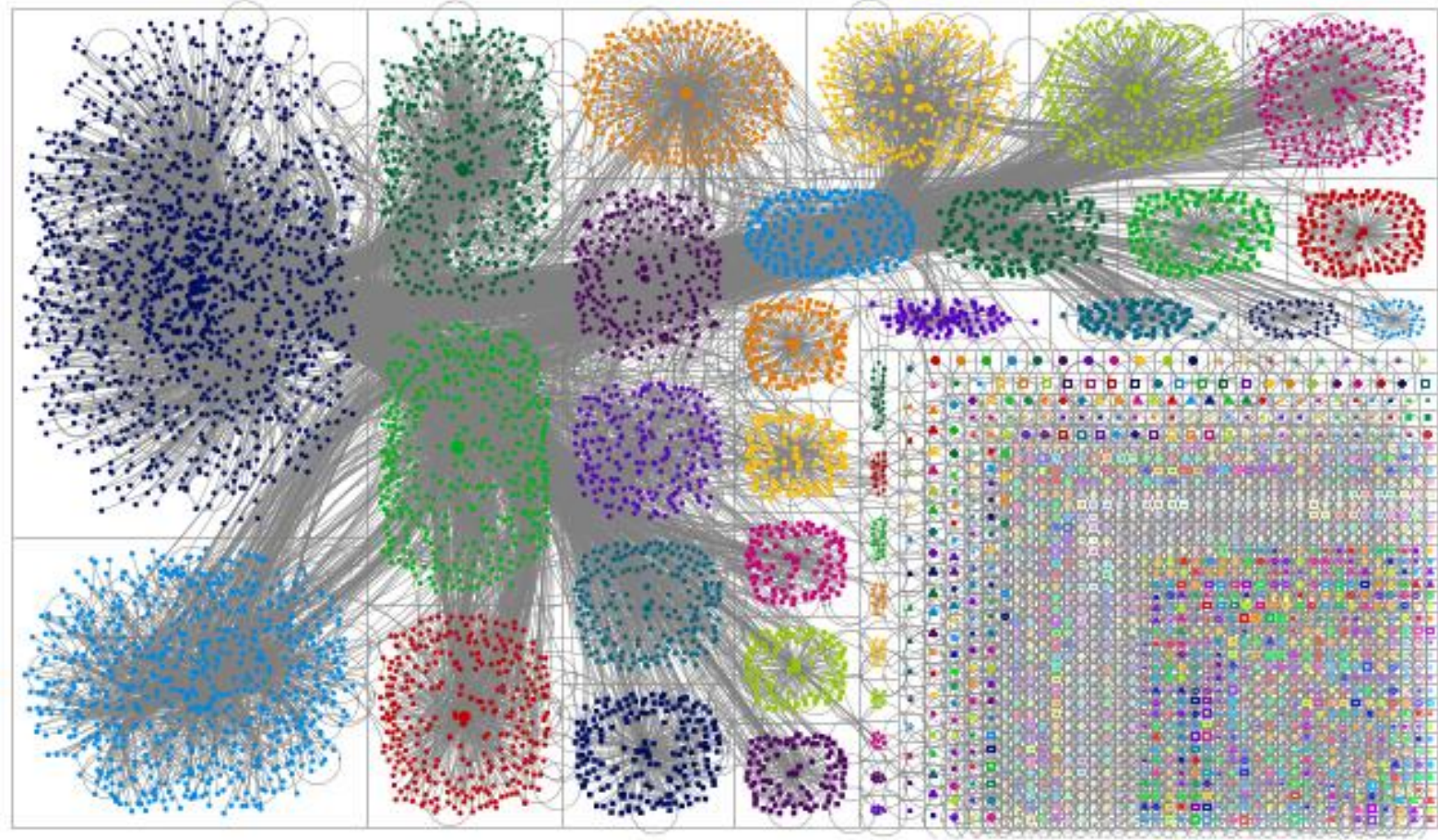

Figura 1 - Grupos de usuários e suas relações

Fonte: Autores.

A partir da análise dos dados apresentados grafo acima, é possível destacar alguns elementos sobre o papel dos atores na rede e das formações de grupos de interação e suas relações. Os dois grupos maiores (azuis à esquerda), além de maiores em número de usuários e conexões, não possuem um nó central com indegree (grau de entrada) muito superior aos outros, como é o caso de outros grupos (como o verde claro e o vermelho, ao lado dos grupos azuis, e laranja na parte mais alta do grupo, que possuem um ator localizado na parte central do cluster e com um tamanho de nó maior que os outros, representando o seu grau de indegree). Isto mostra que há maior diversidade de usuários que reproduzem o discurso destes grupos, também mais generalizado, ainda que geralmente contrário ou crítico à indicação de Moras - próximo de um tom informativo em alguns casos, mostrando a circulação de mensagens informativas, mas com julgamentos de valor, ou seja, de caráter opinativo, em outros casos. $\mathrm{O}$ fato do grupo possuir uma quantidade mais ou menos homogênea de indegree sugere que vários atores receberam igual atenção, possivelmente caracterizando um grupo mais ativista, ou seja, que reproduz os vários tweets de diferentes atores que contém o discurso com o qual existe concordância. Esses dois grupos, ao contrário dos demais, parecem ter um caráter mais ativista na influência da construção da opinião pública na ferramenta.

$\mathrm{Na}$ Tabela 1 vemos quais foram os principais nós com maior grau de entrada, ou seja, que tiveram mais atenção na rede e cujas mensagens foram mais reproduzidas e mencionadas. 
Tabela 1: Nós com maior grau de entrada na rede de conversação

\begin{tabular}{|l|c|}
\hline Nós com maior grau de entrada & Grau \\
\hline cartacapital & 498 \\
\hline deputadofederal & 410 \\
\hline midianinja & 311 \\
\hline benett_ & 300 \\
\hline bslvra & 232 \\
\hline requiaopmdb & 195 \\
\hline stf_oficial & 177 \\
\hline
\end{tabular}

Fonte: Autores.

A presença de nós com alto indegree indica que há atores que foram muito citados, influenciando a conversação de acordo com seus posicionamentos (CHA et al, 2010). O papel desempenhado por estes nós na rede é o de influenciadores (HABERMAS, 1997), visto que seu discurso é fundamental na formação destes grupos menores, onde há maior homogeneidade no posicionamento adotado sobre o caso. Dentre os nós mais citados nos grupos principais estão @ cartacapital e @midianinja (indegree de 498 e 311, respectivamente), ambas contas que divulgaram mensagens criticando a indicação de Moraes. Estes mesmos nós também tem altos graus de centralidade de intermediação (Tabela 2), indicando que foram citados não apenas nesses grupos, mas também por outros.

Tabela 2: Nós com maior grau de intermediação na rede de conversação

\begin{tabular}{|l|c|}
\hline Nós & Centralidade de Intermediação \\
\hline cartacapital & 6024252,935 \\
\hline benett_ & 4220459,606 \\
\hline deputadofederal & 4060279,272 \\
\hline tadeu_alves & 3366497,102 \\
\hline midianinja & 3135625,855 \\
\hline bslvra & 2295676,632 \\
\hline stf_oficial & 2091223,092 \\
\hline o_antagonista & 1886778,748 \\
\hline requiaopmdb & 1743553,277 \\
\hline
\end{tabular}

Fonte: Autores.

Esses nós e os grupos formados em torno de suas mensagens têm grande importância na criação de uma "opinião dominante" no Twitter. Sua influência, seja pelo número de citações, seja pelo grau de intermediação, contribui diretamente para que esses nós tenham um papel determinante na formação da opinião nestes espaços. Esses dados mostram que poucos atores receberam muita visibilidade na filtragem da rede em torno dos conteúdo e podem ser responsáveis pela opinião que a rede mídia social expõe. O grau de intermediação mostra nós que foram citados por grupos diferentes, ou seja, cuja influência vai além dos seus círculos e 
grupos. Além disso, o caráter ativista de vários desses nós, conforme já mencionamos, também contribui para que determinados discursos se sobreponham na ferramenta.

\subsection{Análise de contingência e conteúdo}

A partir da proposta metodológica que descrevemos, podemos observar os principais conceitos que circulam no Twitter a respeito da indicação e suas interconexões na figura a seguir (Figura 2).

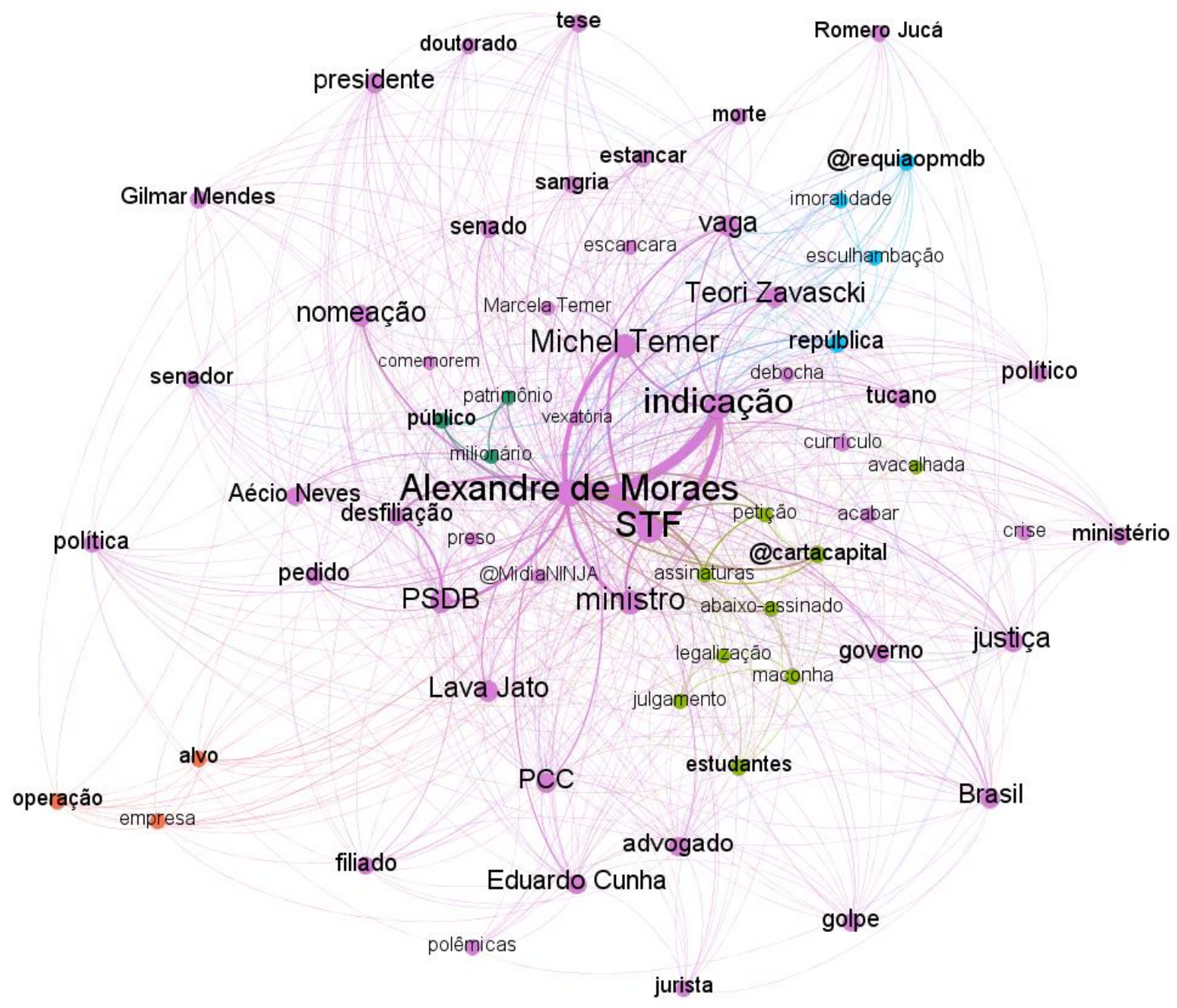

Figura 2 - Grafo gerado a partir da busca por "Alexandre de Moraes" no Twitter

Fonte: Autores.

Os conceitos de cada grupo podem ser visualizados na tabela (Tabela 3 ) a seguir:

Tabela 3 - Grupos e conceitos

\begin{tabular}{|l|l|}
\hline Grupo (FIG. 2) & Conceitos \\
\hline Roxo & $\begin{array}{l}\text { Alexandre de Moraes, STF, indicação, Michel Temer, ministro, nomeação, PSDB, } \\
\text { Lava Jato, PCC, Teori Zavascki, vaga, Eduardo Cunha, advogado, justiça, Brasil, }\end{array}$ \\
\hline
\end{tabular}




\begin{tabular}{|l|l|}
\hline & $\begin{array}{l}\text { presidente, Romero Jucá, tese, doutorado, morte, estancar, sangria, senado, Gilmar } \\
\text { Mendes, senador, político, tucano, Aécio Neves, desfiliação, pedido, política, } \\
\text { ministério, governo, filiado, golpe, jurista, escancara, Marcela Temer, } \\
\text { comemorem, debocha, vexatória, currículo, acabar, crise, preso, @ MidiaNINJA, } \\
\text { polêmicas }\end{array}$ \\
\hline Azul & república, @ requiaopmdb, esculhambação, imoralidade \\
\hline Verde escuro & público, patrimônio, milionário \\
\hline Verde claro & $\begin{array}{l}\text { @ cartacapital, estudantes, avacalhada, petição, assinaturas, abaixo-assinado, } \\
\text { legalização, maconha, julgamento }\end{array}$ \\
\hline Laranja & operação, alvo, empresa \\
\hline
\end{tabular}

Fonte: Autores.

Observando os conceitos que formam o grafo é possível observar que existem expressões que se referem diretamente ao fato da indicação de Moraes (como STF", "indicação", "Temer" e "ministro"), sugerindo mensagens de caráter informativo. Outros conceitos, porém, podem ser identificados a partir de seu sentido opinativo (como "golpe", “debocha", "vexatória", “esculhambação" e "imoralidade”). É possível, portanto, indicar que há informação e também opinião circulando pela rede analisada.

Para identificar que tipo de discursos estão presentes nas conversações nos dados coletados, vamos inicialmente observar as mensagens dos atores de maior indegree e centralidade na rede, de forma a descrever um panorama do que foi dito sobre a indicação de Moraes ao STF.

A Carta Capital (@ cartacapital) é o nó com maior grau de entrada e de intermediação na rede (conforme tabela 1 e 2). O usuário também pode ser identificado na figura 2 no grupo verde claro (próximo ao centro do grafo, deslocado à direita). Ainda que a Carta Capital seja um veículo jornalístico, a sua participação nas conversações em rede é marcada por forte tom opinativo, carregando seus tweets com termos críticos à indicação (FIG 3). Mesmo em matérias de caráter informativo, a Carta Capital mostra seu posicionamento de oposição a Moraes, como quando divulga a petição organizada por estudantes contra o nome de Moraes no STF (FIG 3). Os conceitos "estudantes", "assinaturas", "abaixo-assinado", "petição" e "avacalhada" estão presentes em tweets da Carta Capital coletados nos dados. Três deles podem ser vistos a seguir e ilustram o posicionamento adotado pelo veículo. 

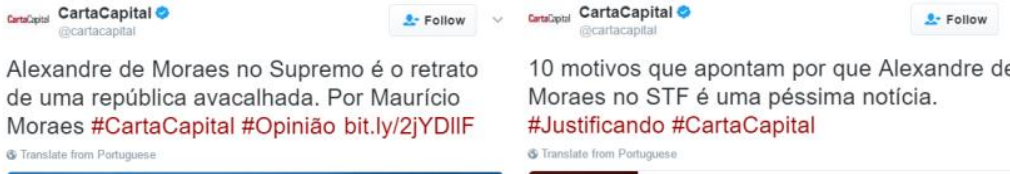
Moraes no STF é uma péssima notícia.

\#Justificando \#CartaCapital

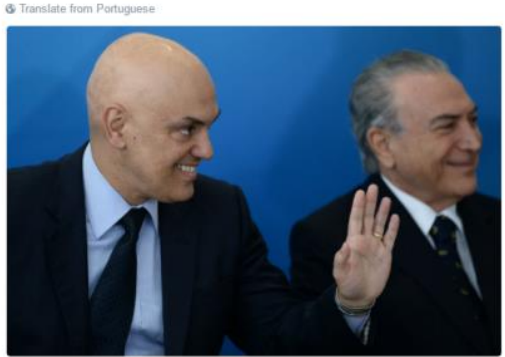

$93 \quad 113$

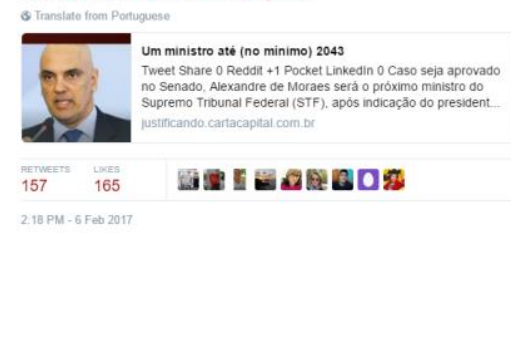

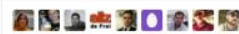

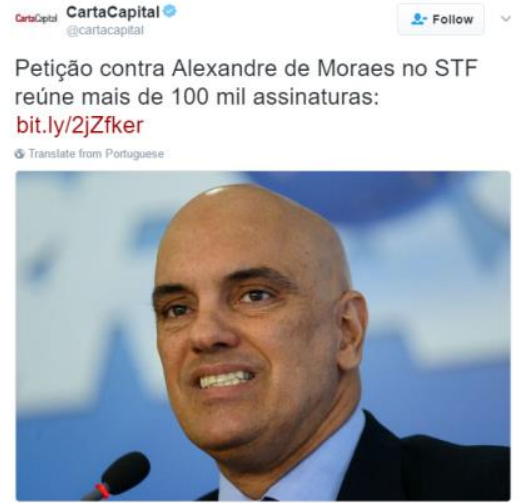

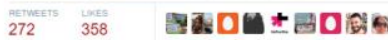

Figura 3 - Tweets de @ cartacapital Fonte: Twitter.

O usuário @deputadofederal é o perfil do político petista Paulo Pimenta, nó com o segundo maior grau de entrada e o terceiro maior grau de intermediação. Um tweet (FIG 4) do político é responsável pela formação do grupo verde escuro (deslocado levemente à esquerda no centro do grafo) da figura 2, composto por três conceitos: "público", "patrimônio" e "milionário". Pimenta questiona com seu tweet a integridade de Moraes, que adquiriu oito imóveis (com valor total de 4,5 milhões de reais) em apenas três anos recebendo um salário de 23 mil reais. Existem também outros tweets (também em tom crítico) do usuário na rede analisada, este, porém é o que alcançou maior circulação.

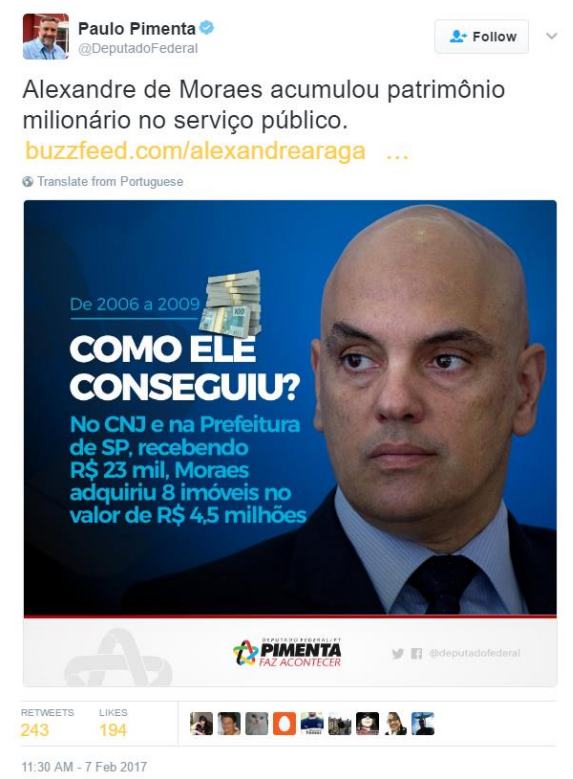

Figura 4 - Tweet de @ deputadofederal (Paulo Pimenta) Fonte: Twitter. 
A Mídia Ninja (@midianinja), veículo de comunicação alternativa, também aparece em destaque na rede (terceiro maior grau de entrada e quinto maior grau de intermediação). O tom dos tweets também é opinativo e crítico à indicação. Em um dos tweets, Moraes é criticado por sua filiação ao PSDB, pela sua atuação como secretário de segurança, por sua atividade como advogado de Eduardo Cunha (político preso por corrupção) e por ter defendido em seu doutorado uma tese que impediria sua indicação ao STF (FIG. 5).

Mídia NINJA

Então, sabe o Alexandre de Moraes?

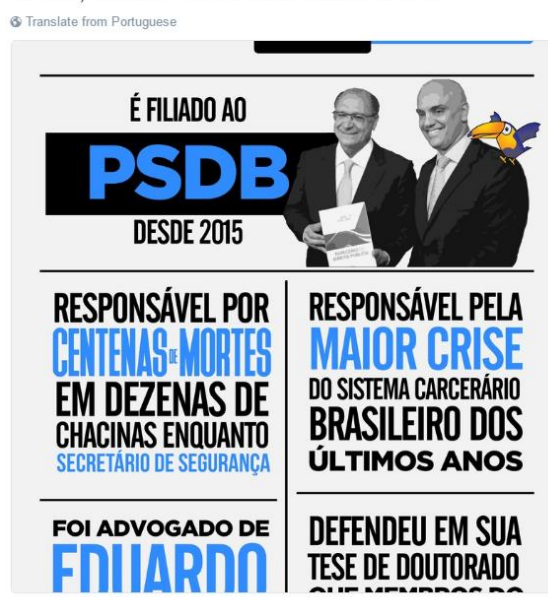

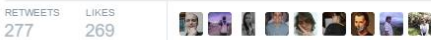

4.14 PM - 7 Feb 201

Figura 5 - Tweet de @midianinja

Fonte: Twitter.

O usuário @benett_se refere ao cartunista de mesmo nome, que divulgou uma charge criticando a indicação de Moraes, ironizando a sabatina em que investigados pela operação Lava Jato seriam responsáveis por questionar Moraes e aprovar sua indicação ao cargo de ministro do STF (FIG. 6). O tweet de @ benett_alcançou números expressivos de RT (1208) e likes $^{7}$ (1157), comprovando sua importância na rede de discussão. Também irônico é o tweet de @bslvra, que sugere que após a desfiliação do PSDB (incluindo também os conceitos "PSDB" e "desfiliação" da figura 2), Moraes poderia ser preso (sugerindo que políticos do partido não são presos pela operação Lava Jato), como pode ser visto abaixo (FIG. 6). Os dois tweets de usuários com altos graus de entrada e intermediação se apropriam do humor para gerar uma opinião contrária à indicação de Moraes.

\footnotetext{
${ }^{7}$ Usuários do Twitter podem utilizar a ferramenta like (curtir) para dar suporte a uma mensagem produzida por outro usuário.
} 


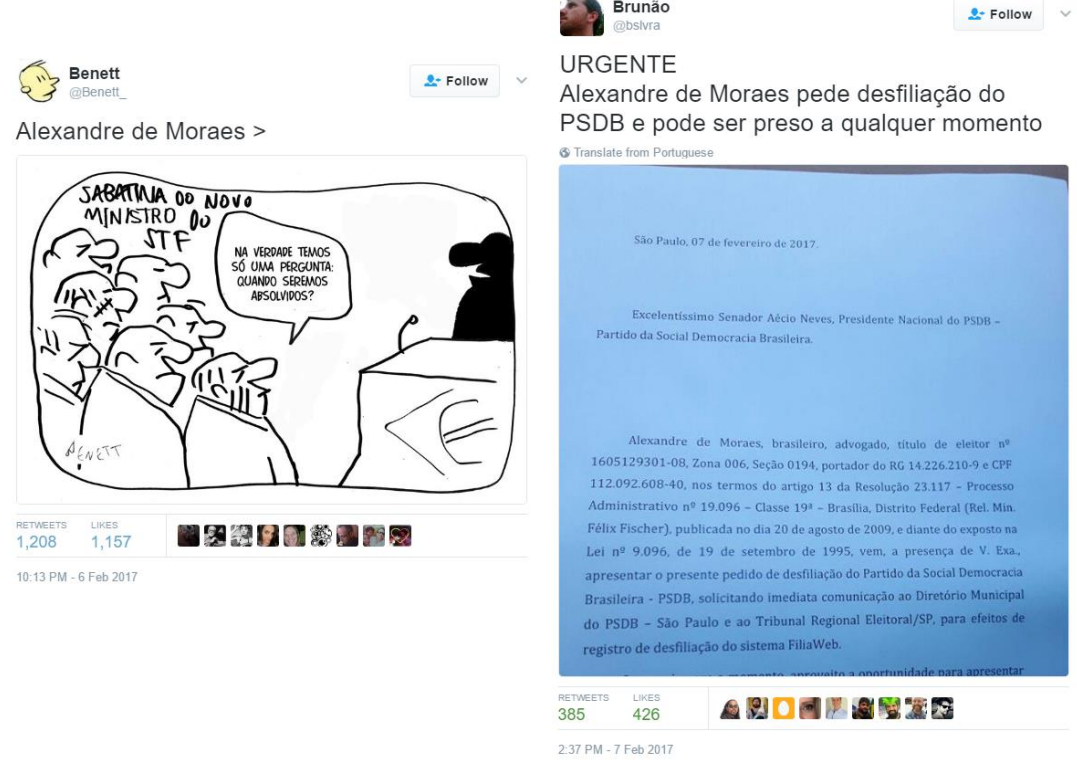

Figura 6 - Tweets de @bennet_e @bslvra

Fonte: Twitter

Ainda entre os nós de maior grau de entrada (e também presente entre os graus de maior intermediação), se pode identificar o usuário @ requiaopmdb, do político Roberto Requião. Um tweet de Requião (FIG. 7) alcançou 1.660 RT e foi o responsável pela formação do grupo azul (na parte superior direita do grafo) da figura 2, composto por conceitos presentes na mensagem que produziu ("república", "esculhambação" e "imoralidade"). O tweet de Requião contém forte crítica à indicação de Moraes para a vaga de Teori e, assim como o tweet de @benett_, os números de retweets e os 2.110 likes $^{8}$ que recebeu demonstram a importância do ator na rede.

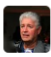

Roberto Requião ?

A indicação de Alexandre Moraes para vaga de

Teori não é uma imoralidade, é acima de tudo

uma esculhambação da República.

๑ Translate from Portugues

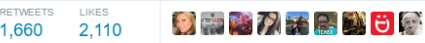

3:19 PM - 6 Feb 2017

Figura 7 - Tweet de @ requiaopmdb

Fonte: Twitter.

Dentre os nós com maior grau de intermediação, o usuário @tadeu_alves se destaca principalmente por sua atividade conversacional, porque não possui nenhum tweet de maior visibilidade, como os nós de maior grau de entrada, mas participa de conversações com outros

\footnotetext{
${ }^{8}$ Usuários do Twitter podem utilizar a ferramenta like (curtir) para dar suporte a uma mensagem produzida por outro usuário.
} 
usuários da rede, conectando, assim, grupos diversos. Já o usuário @o_antagonista aparece também por participar ativamente da conversação, mas, neste caso, tem tweets de maior repercussão, gerando não só a conexão entre grupos, mas também influenciando a opinião de outros atores da rede. É interessante observar o conteúdo dos tweets do usuário @o_antagonista, porque em um dos casos, mostra-se a favor da indicação de Moraes - ainda que use um texto em formato mais próximo do informativo no tweet, a referência ao site da página mostra o apoio - (primeiro tweet da FIG. 8). Já em outro, o tweet conota um posicionamento contrário, defendendo que é preciso reagir à indicação (segundo tweet da FIG. 8). Há também o contexto apenas interpretativo da situação, como no terceiro tweet abaixo.
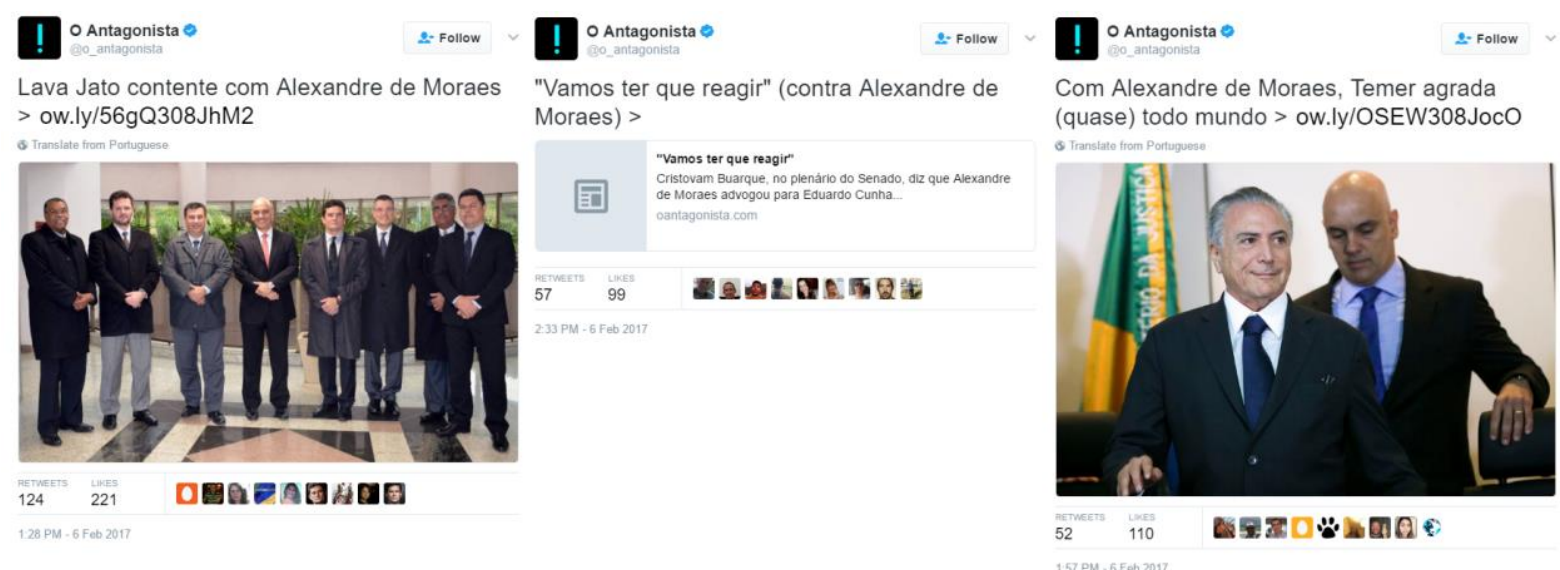

Figura 8 - Tweet de @o_antagonista Fonte: Twitter.

Além do conteúdo observado nos tweets dos nós de maior graus de entrada e intermediação, existem outros conceitos no grafo da figura 2 que podem ser observados para compreender os sentidos por eles gerados na discussão analisada. Além dos pontos apontados acima, também é possível identificar críticas a Moras em função de sua ligação com a facção criminosa "PCC", que aparece em um tweet da usuária@dilmabr (Dilma Bolada), perfil de humor que usa Dilma Rousseff como personagem, em conjunto com conceitos que já surgiram antes, como "PSDB" e "Cunha" (FIG. 9). O conceito "Teori Zavaski" aparece muitas vezes em notícias jornalísticas, de tom informativo, mas também é utilizado em contextos de crítica, como no tweet do usuário @blogdonoblat (do jornalista Ricardo Noblat), em que chama a indicação de Moraes de segunda morte de Teori (FIG. 9). Há ainda a utilização dos conceitos "PSDB" e "Lava Jato" para questionar a integridade de Moraes para julgar o caso (tweet do centro da FIG. 9). As referências aos conceitos "Romero Jucá", 
“estancar" e "sangria" se referem a um áudio do político Romero Jucá em que se falava sobre um acordo nacional para frear as investigações do Lava Jato, sugerindo a indicação de alguém de confiança para o STF, sugerindo que Moraes seria esse nome (dois últimos tweets da FIG. $9)^{9}$.
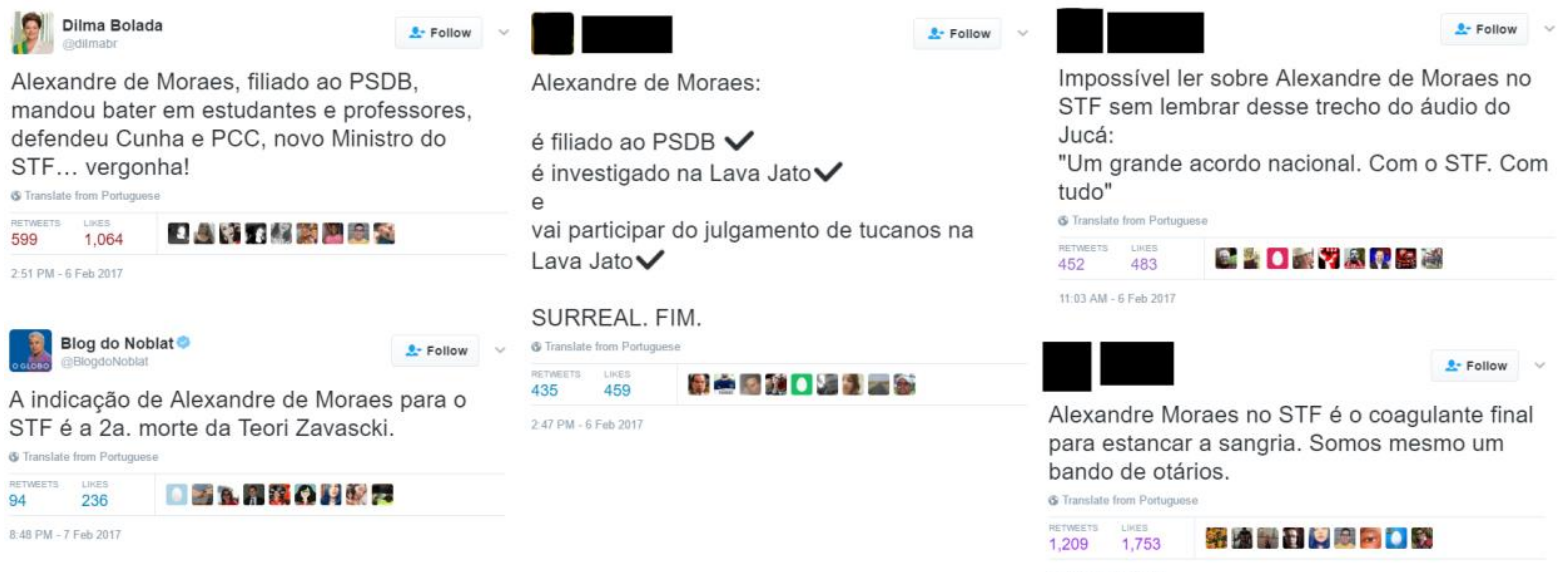

Figura 9 - Tweets com outros conceitos importantes do grafo da figura 2 Fonte: Twitter.

Ainda que tweets neutros, como notícias de caráter informativo publicadas por veículos de opinião, sejam frequentes nos dados coletados, a maior parte dos usuários produz discursos de posicionamentos críticos à indicação de Moraes para o STF, oriundos da própria estrutura de retweets e citações da rede observada. Moraes foi questionado por diversos lados, inclusive por meios de comunicação, que apresentavam, dentre outros temas: 1) seus problemas como ministro da Justiça; 2) sua amizade pessoal com Michel Temer; 3) sua proximidade com o PSDB; 4) sua associação com o PCC e Eduardo Cunha; 5) a contradição com o que foi defendido em sua tese de doutorado; e 6) a petição de estudantes contra sua nomeação.

Importante atentar também ao papel desempenhado por influenciadores (HABERMAS, 1997) neste processo, como: 1) veículos jornalísticos, como a Carta Capital (nó com os maiores graus de entrada e de intermediação), e jornalistas que se posicionaram contra a indicação; 2) páginas de grande visibilidade, importante na circulação de informações (CHA et al, 2010), na internet como Dilma Bolada; 3) políticos da oposição, como Paulo Pimenta (@deputadofederal, com altos graus de entrada e de intermediação); e 4) até mesmo Roberto Requião (também com altos graus de entrada e intermediação), membro do PMDB, partido de Michel Temer. Neste caso específico, observamos que o papel dos influenciadores

\footnotetext{
${ }^{9}$ Os tweets de usuários sem conhecimento público e que não estavam na lista de maior grau e intermediação foram anonimizados na reprodução neste artigo.
} 
(HABERMAS, 1997) desempenhado por usuários com alto grau de intermediação e alto grau de entrada, gerados pela filtragem da própria rede, salienta a presença de opiniões vistas com concordância pela rede e é essencial para o fortalecimento de uma tomada de posição na opinião pública. São esses influenciadores que acabam por lapidar as opiniões através da visibilidade e atenção que recebem (CHA et al, 2010). A credibilidade de Moraes, ao ser associado com instituições e políticos de reputação negativa, além de ser alvo das inúmeras críticas por diversos motivos, como os citados acima, acaba por ser abalada em um processo em que a opinião pública legitima (ou não legitima, neste caso) as ações tomadas pelo poder público (HABERMAS, 1984). Também é possível que o Twitter seja percebido com um espaço que pode influenciar a opinião pública externa, atingindo, através da circulação de informações, outras esferas de posicionamento político (como apontado por BASTOS, 2011). Neste caso, os vários nós da rede atuariam para dar visibilidade para as opiniões das quais compartilham, de modo a tentar influenciar sua rede neste sentido.

Ainda é preciso discutir o papel do Twitter no contexto analisado como espaço que pode ser tomado como esfera pública caracterizada pela relação entre os clusters (BASTOS, 2011) como suas arenas de debates (HABERMAS, 1997) ou como formador de "esferículas públicas", que acabam por se isolar e debater os assuntos apenas uma pequena rede (BRUNS; HIGHFIELD, 2016). Como ilustrado na figura 1, observamos a existências de vários grupos na rede analisada, alguns deles, inclusive, com nós centrais de maior grau de entrada, cercado por nós menores que interagem apenas com o nó de alto grau e alguns outros poucos nós do grupo (como os dois grupos verdes e o vermelho na parte esquerda da imagem e o grupo laranja na parte superior da imagem). Foram encontrados também grupos com maior dispersão, como os dois grupos azuis à esquerda da imagem, que não possuem uma centralidade tão marcada em apenas um nó e se relacionam mais frequentemente com outros grupos da imagem, especialmente com os nós de altos graus de entrada e intermediação que são centrais nos grupos menores. Esses grupos têm características mais ativistas, na medida em que todos os nós reproduzem os discursos de todos, e não apenas de um. É possível identificar, portanto, que existem clusters com usuários isolados, que não interagem com outros clusters, mas há também a presença de influenciadores responsáveis por dar maior visibilidade ao discurso que forma o cluster que faz parte e circular esta informação/opinião na rede (CHA et al, 2010). Sendo assim, se pode afirmar, com base nos dados aqui analisados, que há conexões entre os clusters, ainda que talvez não seja realizada na forma idealizada por Bastos (2011), em que há maior interação entre os atores da rede, sem a dependência de nós 
de alta intermediação que realizam o processo interativo entre os clusters identificados. Há, também, possivelmente uma disputa discursiva, onde alguns grupos atuam de modo a gerar maior visibilidade para aqueles discursos com os quais concordam.

Considerando o papel da conversação em rede observada e descrita no parágrafo acima, se pode afirmar que o Twitter, ao menos no recorte aqui analisado, é um espaço onde há formação da opinião pública. Dentre suas características, há grande importância de atores influentes, responsáveis pela circulação de informações/opinião, além de atuar na formação da opinião de usuários com os quais interagem na rede (HABERMAS, 1997; CHA et al, 2010), além de grupos onde há menor centralidade, mas maior atividade de retweets e menções, caracterizando ações mais ativistas na difusão das opiniões. Ainda que não seja possível afirmar que os posicionamentos identificados no recorte analisado sejam a própria opinião pública como um todo, entendemos que são indícios de opiniões adotadas também em outros espaços, visto que há majoritariamente um posicionamento adotado (contra a indicação de Moraes).

\section{Considerações finais}

O que propomos para este estudo foi analisar a rede no Twitter sobre a indicação de Alexandre de Moraes para o cargo de ministro do STF. A partir de métodos com base na análise de contingência e na análise de redes sociais, foram analisados 15.125 tweets coletados a partir do termo de busca "Alexandre de Moraes". Com isso, se pretendia observar o que se falava sobre Moraes no Twitter, como circulava a informação e a opinião na rede e que tipo de relações havia entre os atores e grupos desta rede.

Foram analisados dois grafos: um que buscava compreender as dinâmicas dos grupos (Figura 1), observando a questão da esfera pública e as relações entre os clusters (HABERMAS, 1997; BASTOS, 2011; BRUNS; HIGHFIELD, 2016), e o papel desempenhado pelos usuários na rede como atores responsáveis por influenciar seus grupos e fomentar a circulação das mensagens (HABERMAS, 1997; CHA et al, 2010); e outro que apresentava as coocorrências entre os conceitos no discurso produzido (Figura 2), utilizado para identificar os posicionamentos mais frequentes entre os usuários e os assuntos debatidos em torno da indicação de Moraes.

A partir da análise dos dois grafos, entendemos que: 1) os tópicos mais frequentes, como esperado, possuem relação direta com a indicação de Moraes e 2) surgem em tom de crítica, questionando a credibilidade de Moraes em função de sua relação com o PSDB, os 
problemas em sua atuação como ministro da Justiça, sua amizade pessoal com Michel Temer, sua associação com Eduardo Cunha e o PCC, a contradição com o que defendeu em sua tese de doutorado e a petição de estudantes contra sua nomeação. Por meio da análise da rede de conversação, 3) foi possível identificar atores com maior influência na rede, alguns deles responsáveis pela formação de grupos em seu redor, com altos graus de entrada e de intermediação, exercendo um papel de influenciador na formação da opinião da rede em seu entorno e da circulação de informação/opinião em outros grupos (HABERMAS, 1997; CHA et al, 2010); assim como 4) a dinâmica entre os grupos da rede mostraram que haviam dois clusters maiores (os azuis à esquerda do grafo da figura 1) que exerceram papel ativista, tendo maior similaridade de indegree entre os nós que os formaram, e haviam outros grupos menores com atores centrais que ocupavam papéis de influência na formação da opinião pública, especialmente entre os nós em seu redor (visto que possuíam alto grau de entrada), observando as dinâmicas entre os atores e grupos, entendemos que há relações entre os clusters - ainda que dependentes de nós de maior grau de intermediação, talvez gerando um contexto diferente do imaginado por Bastos (2011) em que haveria maior proximidade entre todos os atores que fazem parte dos diferentes clusters - o que qualificaria a rede como uma arena da esfera pública composta por outras arenas que se relacionam, conforme imaginado por Habermas (1997). 


\section{Referências}

AZEVEDO, F. A. Agendamento da política. In: ALBINO, A., RUBIM, C. (Org.). Comunicação e política: conceitos e abordagens. Salvador: EDUFBA, 2004. p. 41-71. Disponível em: <https://repositorio.ufba.br/ri/bitstream/ufba/134/4/ComunicaoPolitica_RI.pdf>. Acesso em 23 fev. 2017.

BASTOS, M. T. Public opinion revisited: the propagation of opinions in digital networks. Journal of Arab \& Muslim Media Research, v. 4, n. 2 e 3, p. 185-201, 2011. Disponível em: <http://www.intellectbooks.co.uk/journals/view-Article,id=12567/>. Acesso em 14 fev. 2017.

BOYD, D.; ELLISON, N. B. Social Network Sites: Definition, History, and Scholarship. Journal of Computer-Mediated Communication, v. 13, n. 1, p. 210-230, out. 2007. Disponível em:<http://onlinelibrary.wiley.com/doi/10.1111/j.1083-6101.2007.00393.x/full>. Acesso em 14 fev. 2017.

BRUNS, A.; HIGHFIELD, T. Is Habermas on twitter? social media and the public sphere. In: BRUNS, A.; ENLI, G.; SKOGERO, E.; LARSSON, A.O.; CHRISTENSEN, C. (Orgs.) The Routledge Companion to Social Media and Politics. New York: Routledge, 2016, p.56-73.

CHA, M. H. Measuring user influence on twitter: the million follower fallacy. In: INTERNATIONAL AAAI CONFERENCE ON WEBLOGS AND SOCIAL MEDIA, 40., 2010, Washington. Proceedings... . Washington, 2010. p. 10 - 17.

GARCIA, G. et al. Senado aprova impeachment, Dilma perde mandato e Temer assume. $\mathbf{O}$ Globo. Rio de Janeiro. 31 ago. 2016. Disponível em: <http://g1.globo.com/politica/processode-impeachment-de-dilma/noticia/2016/08/senado-aprova-impeachment-dilma-perdemandato-e-temer-assume.html>. Acesso em: 10 mar. 2017.

GIBSON, R. From Brochureware to 'MyBo': an overview of online elections and campaigning. In: SERRA, P.; CAMILO, E.; GONÇALVES, G. (Org.). Participação Política e Web 2.0. Covilhã: Labcom, 2013. p. 27-38. Disponível em <http://www.labcomifp.ubi.pt/ficheiros/20130417-2013_novos_media_participacao_politica.pdf>. Acesso em: 23 fev. 2017.

HABERMAS, J. Direito e democracia: entre facticidade e validade. Rio de Janeiro: Tempo Brasileiro, 1997. 2 v.

HABERMAS, J. Mudança estrutural da esfera pública: investigações quanto a uma categoria da sociedade burguesa. Rio de Janeiro: Tempo Brasileiro, 1984.

RECUERO, R. GT de Cibercultura da Compós: análise de temas e coautorias. Intexto, Porto Alegre, UFRGS, n. 34, p. 553-570, set./dez. 2015. Disponível em:

<http://www.seer.ufrgs.br/intexto/article/viewFile/58395/35371>.Acesso em: 14 fev. 2017.

RECUERO, R. Redes sociais na internet. Porto Alegre: Sulina, 2010.

RECUERO, R.; BASTOS, M.; ZAGO, G. Análise de redes para mídia social. Porto Alegre: Sulina, 2015. 